Document downloaded from:

http://hdl.handle.net/10251/169144

This paper must be cited as:

Guardiola, C.; Pla Moreno, B.; Bares-Moreno, P.; Barbier, ARS. (2020). Closed-loop control of a dual-fuel engine working with different combustion modes using in-cylinder pressure feedback. International Journal of Engine Research. 21(3):484-496.

https://doi.org/10.1177/1468087419835327

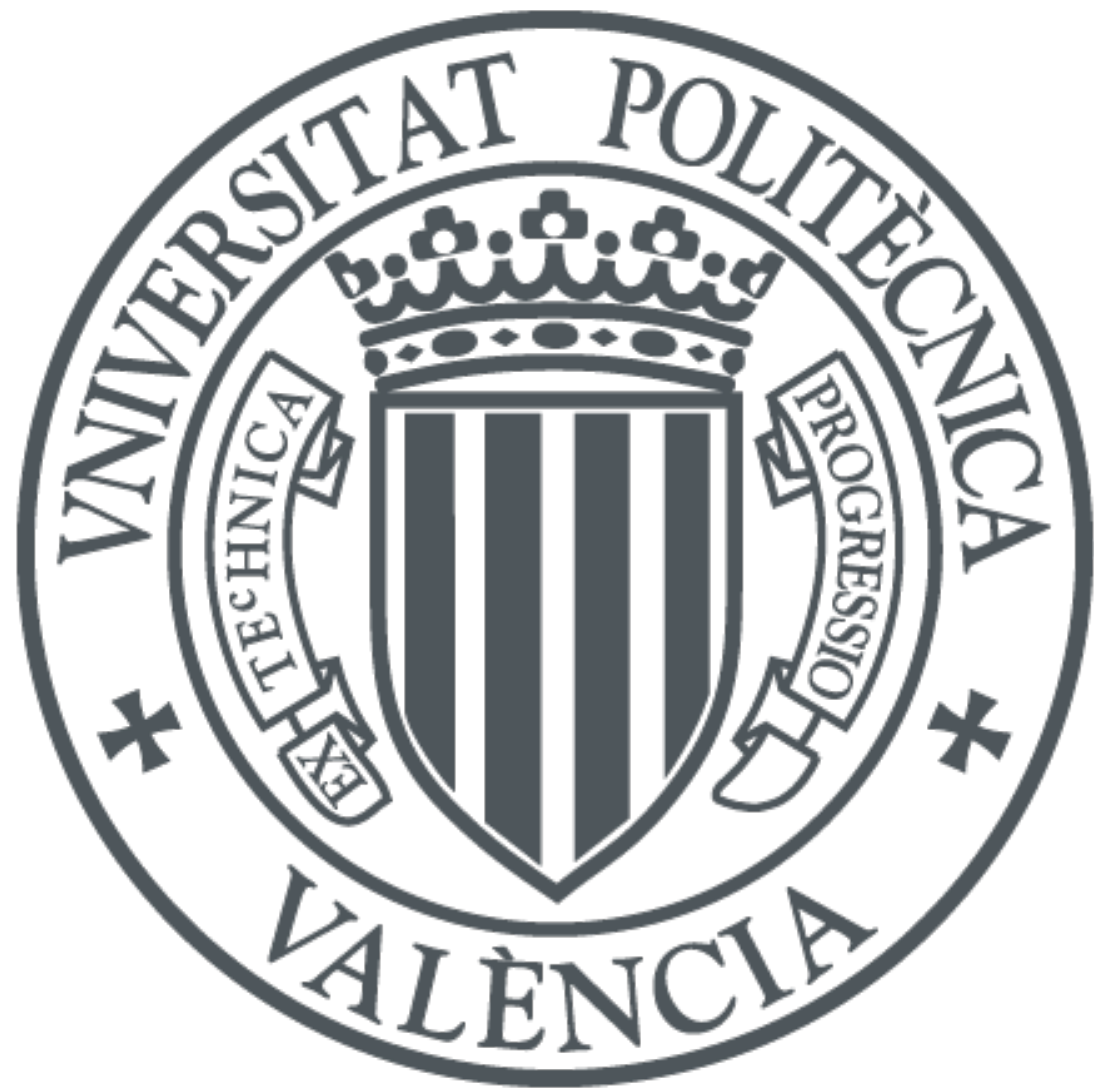

The final publication is available at

https://doi.org/10.1177/1468087419835327

Copyright SAGE Publications

Additional Information

This is the author is version of a work that was accepted for publication in International Journal of Engine Research. Changes resulting from the publishing process, such as peer review, editing, corrections, structural formatting, and other quality control mechanisms may not be reflected in this document. Changes may have been made to this work since it was submitted for publication. A definitive version was subsequently published as https://doi.org/10.1177/1468087419835327. 


\title{
Closed-loop control of a dual-fuel engine working with different combustion modes using in-cylinder pressure feedback
}

\author{
Carlos Guardiola, Benjamín Pla, Pau Bares and Alvin Barbier
}

\begin{abstract}
This work presents a closed-loop combustion control concept using in-cylinder pressure as a feedback in a dual-fuel combustion engine. At low load, Reactivity Controlled Compression Ignition (RCCl) combustion was used while a diffusive dual-fuel combustion was performed at higher loads. The aim of the presented controller is to maintain the Indicated Mean Effective Pressure (IMEP) and the combustion phasing at a target value, and to keep the maximum pressure derivative under a limit to avoid engine damage in all the combustion modes by cyclically adapting the injection settings. Various tests were performed at steady-state conditions showing good abilities to fulfill the expected operating conditions but also to reject disturbances such as intake pressure or Exhaust Gas Recirculation (EGR) variations. Finally, the proposed control strategy was tested during a load transient resulting in a combustion switching-mode and the results exhibited the closed-loop potential for controlling such combustion concept.
\end{abstract}

\section{Keywords}

Reactivity controlled compression ignition, dual-fuel combustion, combustion control, in-cylinder pressure feedback, closed-loop control

\section{Introduction}

Over the years, the research community has been committed to investigate several technologies to comply with the emission restrictions for internal combustion engines ${ }^{1-4}$. Recently, Low Temperature Combustion (LTC) appeared to be a suitable solution to reduce pollutants at the exhaust by reducing $\mathrm{NO}_{\mathrm{x}}$ and soot emissions at the source instead of meaning of after-treatment systems ${ }^{5,6}$. In this sense, combustion modes such as Homogeneous Charge Compression Ignition (HCCI) were investigated showing a good potential ${ }^{7-9}$. However, limited operating range, low combustion control and excessive unburned products were identified $^{10,11}$. For this reason, other LTC concepts were investigated such as Reactivity Controlled Compression Ignition (RCCI) which demonstrates to be one of the most promising alternatives ${ }^{12-14}$. This strategy consists in a dualfuel combustion (DFC) using a low and a high reactivity fuel ${ }^{15-17}$ and where the combustion phasing is controlled by modulating the blending ratio of the two fuels ${ }^{18-20}$. RCCI combustion is however limited in load operation mainly due to the high pressure derivative levels obtained. Hence, to extend the operating range, solutions have been highlighted such as decreasing the engine compression ratio ${ }^{21,22}$ or adding a late direct injection of the high reactivity fuel in a diffusive dual-fuel (DDF) combustion mode ${ }^{23}$.

Due to their challenging controllability, low temperature combustion concepts drove the research community to develop advanced control strategies ${ }^{24-27}$ and the use of an in-cylinder pressure sensor for a proper combustion analysis and feedback diagnostic is generally assumed to be a high potential solution $^{28-30}$.
Different closed-loop control applications for controlling dual-fuel engines can be found in literature. Olsson et al. ${ }^{31}$ implemented a closed-loop (CL) control using in-cylinder pressure feedback in a dual-fuel HCCI multi-cylinder engine. The control was achieved using a Proportional Integral Derivative (PID) controller on the total fuel amount injected for controlling the load and on the fuel blending ratio for the combustion timing control which was gain-scheduled due to the sensitivity of the crank angle of $50 \%$ heat release (CA50) to the operating conditions. Such control strategy showed the capability to correct injection settings up to 6.5 bar Indicated Mean Effective Pressure (IMEP) at an engine speed between 700 and $2000 \mathrm{rpm}$. Ott et al. ${ }^{32}$ investigated the control of the combustion phasing and the combustion noise, through the Maximum Pressure Rise Rate (MPRR), in a natural gas-diesel engine. In this case, the natural gas was port-injected while the diesel was direct injected. The CA50 and the MPRR were controlled by manipulating the Start Of Injection (SOI) and the duration of the diesel injection. The system was linearized and Proportional Integral (PI) actions were applied. The experimental tests were performed at a constant engine speed of $2000 \mathrm{rpm}$ and varying the engine load from approximately 3 to 15 bar Brake Mean Effective Pressure

CMT - Motores Térmicos, Universitat Politècnica de València, Camino de Vera s/n, E-46022 Valencia, Spain

\section{Corresponding author:}

Alvin Barbier, CMT - Motores Térmicos, Universitat Politècnica de València, Camino de Vera s/n, E-46022 Valencia, Spain.

Email: albar9@mot.upv.es 
(BMEP) showing the controller ability to control both CA50 and MPRR but also to compensate variations in the intake manifold pressure or the Exhaust Gas Recirculation (EGR) rate. In the so named RCCI combustion, Hanson and Reitz ${ }^{33}$ compared Conventional Diesel Combustion (CDC) and RCCI under transient operations. Both openloop (OL) and closed-loop control were studied including a PID controller on the combustion phasing by adjusting the Port Fuel Injection (PFI) ratio. The experimental results proved that load transient conditions, from 1 to 4 bar BMEP at $1500 \mathrm{rpm}$, were possible with an RCCI combustion. Khodadadi Sadabadi and Shahbakhti ${ }^{34}$ proposed a controller to track the desired CA50 by modulating the premixed ratio (PR) of the two fuels. First they created a controloriented model (COM) to predict the combustion phasing, which was then simplified and linearized in order to develop a linear observer-based feedback controller. The control strategy demonstrated satisfactory results to track the CA50 but also to maintain it to its reference value with external disturbances. Similarly, Kondipati et al. ${ }^{35}$ designed a controller to track the combustion phasing in a RCCI combustion engine by modulating either the PR or the SOI of the direct injected fuel (n-heptane). A control-oriented model was developed for predicting the start of combustion and the CA50 and, after being validated under steady-state and transient operation, this COM was used to tune the PI gains of the closed-loop control. Finally, such gains were applied and the control strategy was experimentally evaluated by performing CA50 steps showing an average tracking error of 2 CAD. More recent work presented by Arora and Shahbakhti ${ }^{36}$ was dedicated to a closed-loop control in a light-duty RCCI engine. Based on PI actions, they suggested the use of a sensitivity map to control the combustion phasing either in terms of premixed ratio or SOI of the high reactivity fuel while the IMEP was obtained by controlling the total amount of fuel injected. Results showed that the controller was able to reach desired load under transient operation but also to maintain the CA50 at a target value. Indrajuana et al. ${ }^{37}$ used a multi-zone combustion model for designing a Multiple Input Multiple Output (MIMO) feedback control applied on a natural gas-diesel RCCI engine. The controller used the SOI of the diesel injection, the diesel and natural gas fuel quantities as control variables for tracking the desired ignition delay, IMEP and blend ratio (BR). Reference tracking and disturbance rejection were evaluated by simulation showing the capability of the controller to decouple the iteraction between the controlled variables with satisfactory results. Recently, Raut et al. ${ }^{38}$ investigated a model predictive control (MPC) for tracking the IMEP and the CA50 by adjusting the total fuel quantity and the SOI of the n-heptane fuel, respectively, in an RCCI engine. The MPC was chosen for its capacity to include constraints such as the covariance in the IMEP $\left(C O V_{I M E P}\right)$. Furthermore, in order to extend the operating range of the controller, MIMO MPCs were designed where the premixed ratio was selected as the scheduling variable. The controller was experimentally tested and showed to be able to track the desired IMEP and CA50 over a range of PR variations. Some work were dedicated at developing combustion modeswitching strategies in dual-fuel engines, such as the one presented by Indrajuana et al. ${ }^{39}$. In this case, Conventional
Dual Fuel (CDF) and RCCI combustion in a natural gasdiesel engine were considered. The proposed strategy was based on air-fuel path feedback controllers and static inputoutput decoupling to ease the implementation of the modeswitching controller. Simulation data were used to evaluate the controller at low load and stationary conditions showing stable operation during a mode-switching.

This work presents a real-time cycle-to-cycle closedloop combustion control using the in-cylinder pressure signal as a feedback applied to a dual-fuel combustion engine. A control concept is designed for controlling the IMEP and the combustion phasing at a desired value while keeping the MPRR under a defined and safe threshold in all the combustion modes used over the engine map (RCCI to DDF). Two experimental validations are presented, being a disturbance rejection at stationary conditions and a significant IMEP transient from low to high load including combustion mode switching without exceeding the operation limits. The developed control application uses a real-time data acquisition and processing system combined with an embedded FPGA real-time controller for the injection management. Experimental tests were conducted in a medium-duty engine using gasoline as the port-injected fuel and diesel for the Direct Injection (DI).

This paper is subdivided into the following sections: first, the experimental setup is described in Section 2 including the engine test bench configuration and the acquisition/control application. Section 3 presents the studied combustion modes in order to define the injection strategies in each of them and in Section 4 the proposed control concept is detailed introducing the different strategies developed. Finally, the experimental results are presented and discussed in Section 5 showing the controller ability to maintain the desired performance under steady-state and transient operation.

\section{Experimental setup}

The experimental tests were performed in a multi-cylinder medium-duty diesel engine where one of the cylinders was equipped to run under dual-fuel operation. This "singlecylinder" research engine was controlled using an in-house controller, described later in this section, while the rest of the cylinders were managed by the stock Engine Conrol Unit (ECU). In order to extend the operating range of the RCCI combustion, the piston bowl volume was modified for having a Compression Ratio (CR) of 15.3:1. Table 1 presents the main engine characteristics.

In order to operate the engine in dual-fuel combustion, an additional port fuel injection system was installed at the intake manifold of the research cylinder. Figure 1 shows the fully instrumented engine including the facilities of both "single-cylinder" and multi-cylinder part of the engine. As it can be seen in this figure, a screw compressor was used to supply the boosted air to the research single-cylinder engine intake and an additional air-loop was in charge of the exhaust gas recirculation. The EGR rate can be estimated using the measurement of both the $\mathrm{CO}_{2}$ concentration at the exhaust and at the intake using the equation (1) with the atmospheric concentration $\left[\mathrm{CO}_{2}\right]_{\mathrm{atm}}=0.04 \%$. 
Table 1. Engine specifications

\begin{tabular}{ll} 
Number of cylinders & 4 \\
Bore $x$ Stroke & $110 \mathrm{~mm}$ x $135 \mathrm{~mm}$ \\
Crank length & $67.5 \mathrm{~mm}$ \\
Total displacement & $5100 \mathrm{~cm}^{3}$ \\
$\begin{array}{l}\text { Compression ratio } \\
\text { (nominal) }\end{array}$ & $17: 1$ \\
$\begin{array}{l}\text { Compression ratio } \\
\text { (RCCl configuration) }\end{array}$ & $15.3: 1$ \\
\hline
\end{tabular}

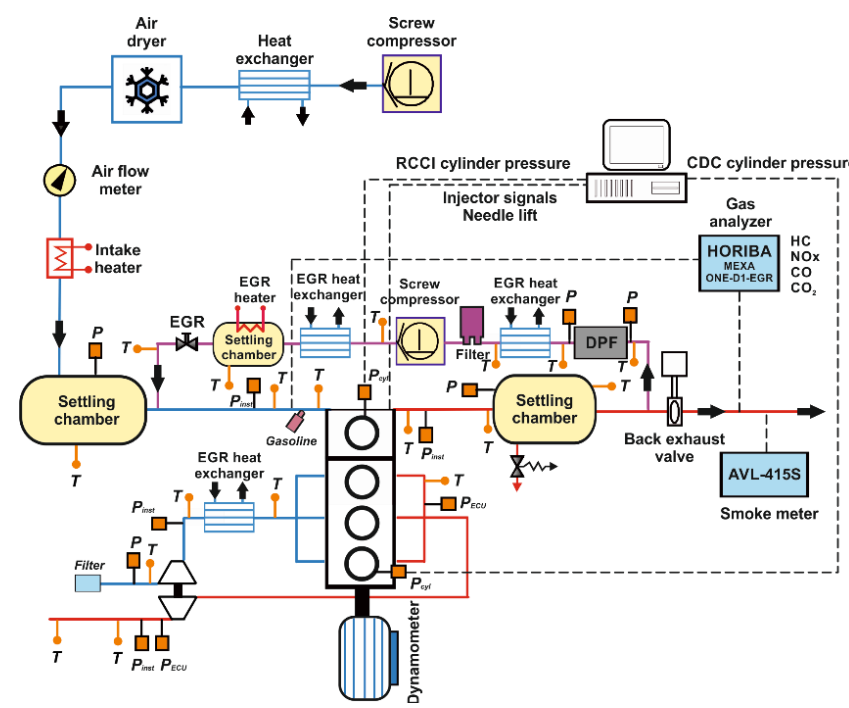

Figure 1. Engine test bench setup

$$
E G R=\frac{\left[\mathrm{CO}_{2}\right]_{\text {int }}-\left[\mathrm{CO}_{2}\right]_{\mathrm{atm}}}{\left[\mathrm{CO}_{2}\right]_{\text {exh }}-\left[\mathrm{CO}_{2}\right]_{\text {atm }}}
$$

In this study, regular diesel (DI) and 95 octane number gasoline (PFI) were used as high and low reactivity fuels, respectively. More details about injectors, fuels and instrumentation can be found in previous work presenting the full load engine operation ${ }^{23}$.

The in-cylinder and intake pressure signals were measured using respectively Kistler $6125 \mathrm{C}$ and $4045 \mathrm{~A} 10$ sensors. The analog signals were acquired using a PXIe-6356 card from National Instruments capable of simultaneously acquiring 8 channels at a sampling frequency up to $1.25 \mathrm{MHz} /$ channel and the sampling frequency was set using a research encoder resulting in a crank angle based acquisition with 0.2 Crank Angle Degree (CAD) resolution. Then, a PXIe-8135 module was used to analyse, process, and store the data. This device includes a $2.3 \mathrm{GHz}$ quad-core Intel Core i7 processor ensuring a fast and reliable computation. The port fuel and direct injectors were connected to a real-time cRIO-9024 controller synchronized with the camshaft and crankshaft signals. Both, PXIe-8135 and cRIO-9024, were connected by Ethernet protocol to a computer for programming algorithms and visualizing the data in LabVIEW software. Figure 2 summarizes the hardware architecture of the control system.

The in-cylinder pressure pegging was done using the intake manifold pressure near the intake Bottom Dead Center (BDC) ${ }^{41}$ and a Butterworth low-pass filter, tuned at $3 \mathrm{kHz}$ for removing high frequency components, was applied. Finally, the combustion phasing calculation was performed using the
Apparent Heat Release Rate (AHRR) presented in equation $(2)^{42}$ :

$$
\begin{aligned}
\operatorname{AHRR}(\theta) & =\frac{k}{k-1} \cdot P_{c y l}(\theta) \cdot d V(\theta) \\
& +\frac{1}{k-1} \cdot V(\theta) \cdot d P_{c y l}(\theta)
\end{aligned}
$$

with $\theta$ the crank position, $k$ a constant polytropic coefficient, $P_{c y l}$ the in-cylinder pressure and $V$ the instantaneous chamber volume.

\section{Combustion modes}

With the aim of achieving dual-fuel operation into the whole engine map, maximum pressure derivative (MPRR) and incylinder pressure $\left(\mathrm{P}_{\max }\right)$ limits were set to $15 \mathrm{bar} / \mathrm{CAD}$ and 190 bar respectively. According to such limitations, three different strategies have been investigated ${ }^{23}$ :

- RCCI Fully-Premixed (FP), from idle up to $40 \%$ load, corresponding approximately to 8 bar IMEP: this combustion type is achieved using advanced double diesel injections allowing a high mixing time before the Start Of Combustion (SOC), resulting in ultralow $\mathrm{NO}_{\mathrm{x}}$ and soot levels. In this strategy, the load is achieved by acting on the total premixed charge and the combustion phasing is governed by the fuel reactivity through the gasoline fraction (more gasoline delaying the combustion). At these low loads, the MPRR levels are low enough to not represent a risk for the engine.

- RCCI Higly-Premixed (HP), from $40 \%$ up to $75 \%$ load, about 15 bar IMEP: when reaching higher loads, the previous mode is limited by the pressure derivative levels due to the abrupt auto-ignition of the premixed charge. Thus, for achieving the desired load while maintaining the MPRR at a safe threshold, the second diesel injection is delayed near the Top Dead Center (TDC). Nevertheless, due to the lack of premixing time for the late diesel injection, this strategy provides higher soot levels but $\mathrm{NO}_{\mathrm{x}}$ emissions can still be achieved below EURO VI limit under specific operating conditions (intake pressure, EGR, etc.).

- Diffusive Dual-Fuel (DDF), from $75 \%$ up to full load: in this strategy, in order to increase the load without exceeding the mechanical constraints, only one single late diesel injection is used in addition to the gasoline. In this case, the location of this diesel injection becomes the main variable for combustion phasing control. The AHRR is composed of an abrupt peak due to the combustion of the premixed mixture followed by a long diesel-like combustion during the expansion stroke (see right plot of Figure 3). However, because of the diffusive nature of this combustion operation, $\mathrm{NO}_{\mathrm{x}}$ emissions cannot be maintained under EURO VI limit and high soot levels are obtained.

Figure 3 (left plot) presents the aforementioned injection strategies for each combustion mode. The blue square represents the gasoline injection which is injected during the 


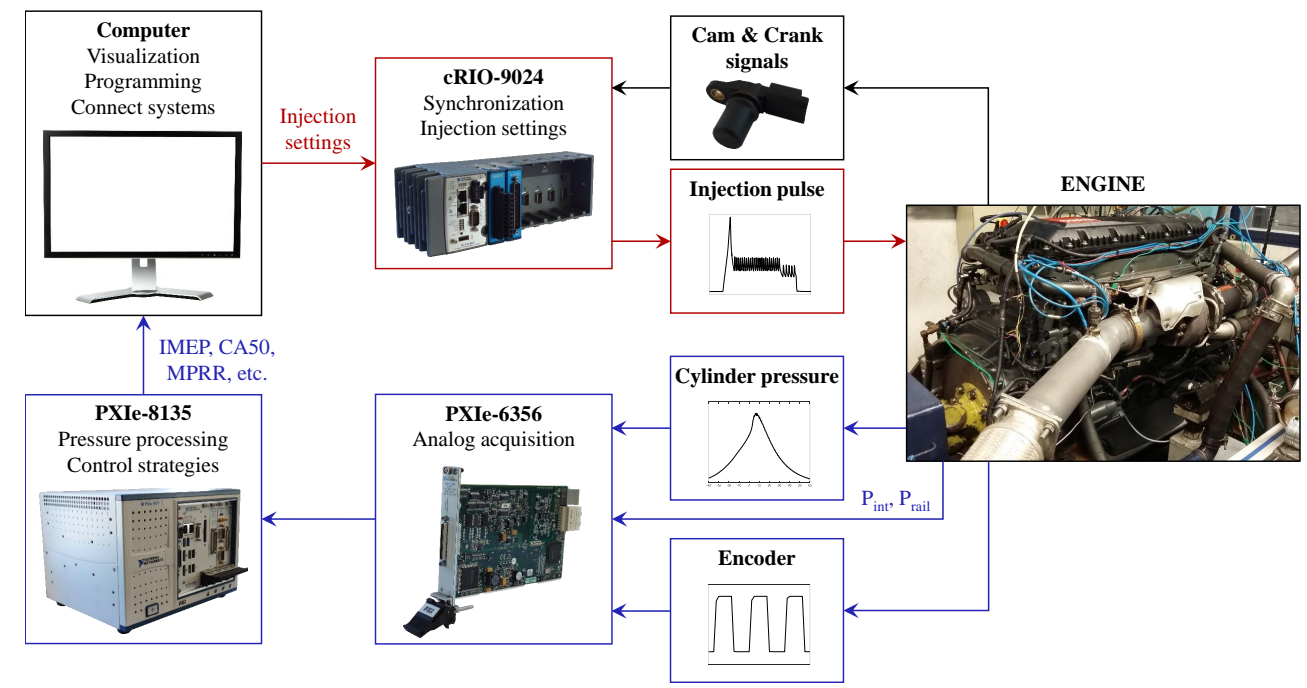

Figure 2. Hardware architecture - acquisition and processing actions (blue) and control actions (red)

intake stroke. In RCCI FP, D1 and D2 are used as early diesel injections (in green) where the sum of their masses corresponds to the premixed diesel fuel mass $m_{d i, p r e}$. In RCCI HP combustion mode, the diesel injection D2 is moved near the TDC and is then considered as a post injection while D1 remains a part of the premixed charge. Finally, in DDF, the injection D1 is not used anymore and only one single post diesel injection is performed in addition to the gasoline.

As a summary, the presented combustion modes are managed by the following injection parameters: the gasoline mass $m_{\text {gas }}$, the premixed diesel mass $m_{\text {di,pre }}$ (including $m_{D 1}$ and $m_{D 2}$ ), and the post diesel injection through its mass $m_{\text {di,post }}$ and its start of injection $S O I_{\text {post }}$.

\section{Control system}

Common open-loop control is based on look-up tables storing the control variables usually as a function of the load and the engine speed. The main drawback of such method is that if the operating conditions (intake pressure, EGR, air mass, etc.) are not exactly as expected, undesired performance could be obtained. Hence, a closed-loop control was programmed for achieving the desired IMEP and combustion phasing and for limiting the MPRR under a safe range by correcting the open-loop settings by means of PI controllers to define the final control actions. In this work, instead of the common CA50, the combustion phasing was estimated through the parameter known as the combustion centroid $^{43}$ that the authors named the Crank Angle combustion Center of Gravity (CACG) in this work. This choice is justified by an important CA50 cycleto-cycle variation when working under high load dualfuel combustion. More details about such parameter can be found in appendix A. The in-cylinder pressure signal was used to calculate the combustion metrics and such values were fed back to the controllers. A low-pass filter was applied to calculate the error between the desired value and the value obtained at the previous cycle to avoid control instabilities and encompass normal cyclic variability. In order to simplify the control strategies and their implementation, the previously cited injection quantities were rearranged and the control concept results then into four basic control parameters:

- The preximed fuel mass $m_{\text {pre }}$ (equation (3))

- The gasoline fraction of the premixed mass $G F_{\text {pre }}$ (equation (4))

- The start of injection of the post diesel injection $S O I_{\text {post }}$

- And finally the total fuel mass $m_{t o t}$ (equation (5))

$$
\begin{gathered}
m_{\text {pre }}=m_{\text {gas }}+m_{\text {di,pre }} \\
G F_{\text {pre }}=\frac{m_{\text {gas }}}{m_{\text {pre }}} \\
m_{\text {tot }}=m_{\text {pre }}+m_{\text {di,post }}
\end{gathered}
$$

The premixed diesel mass $m_{\text {di,pre }}$ can be achieved through one single injection or splitted into two early diesel injections as introduced in Figure 3. The aforementioned control parameters are stored in look-up tables for conventional open-loop control as a function of the current engine speed and the desired IMEP. These values are then closed-loop corrected in order to reach the desired performance. The rest of the control variables such as $S O I_{g a s}$ or $S O I_{D 1}$ are considered as calibration parameters (also stored in look-up tables) and are not varied by the controller. Figure 4 presents the closed-loop control concept used in this work. The control actions for each parameter modulated by the PI controllers in Figure 4 are explained below:

IMEP control. As it can be seen in Figure 4, the engine load is directly controlled by the total fuel mass injected $m_{\text {tot }}$. Thus, the more the total fuel mass the more the load at the engine output.

CACG control. In this concept, although the CACG is controlled by using a single output PI controller, the corrections are applied to two control parameters: the gasoline fraction $\left(G F_{\text {pre }}\right)$ and the start of the post injection $\left(S O I_{\text {post }}\right)$. First, while the combustion phasing can be reached by using the premixed charge, only $G F_{p r e}$ is 

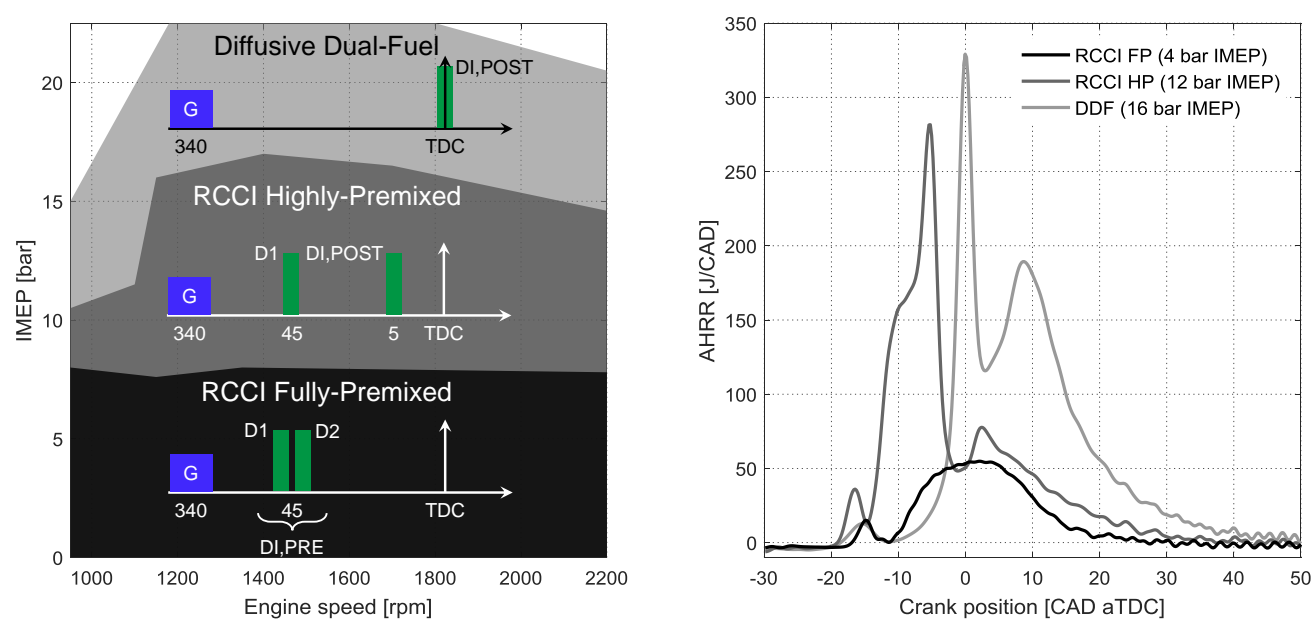

Figure 3. $\mathrm{RCCl}$ combustion concept: injection strategies (left) and non-exhaustive AHRR profiles of the three presented combustion modes (right)

controlled in order to modify the reactivity of the fuel mixture. However, when $G F_{\text {pre }}$ approaches 1, meaning that the premixed fuel mass is limited due to the MPRR level and only gasoline is injected, such control parameter cannot be more extended and thus the $S O I_{\text {post }}$ starts to control the CACG. Figure 5 describes the logic behind the CACG controller, where $\varepsilon_{C A C G}$ corresponds to the error between the desired CACG value and the measured feedback and $\triangle u$ corresponds to the control corrections.

MPRR control. Finally, when the actual MPRR has been detected as above a limit the control starts to correct the premixed charge to maintain the MPRR level to the desired limitation. To control such parameter, the actions are applied to the premixed mass $m_{\text {pre }}$ as presented in equations (6) and (7).

$$
\begin{array}{r}
\Delta m_{\text {pre }}=k_{p} \cdot \varepsilon_{M P R R}+ \\
k_{i} \int \varepsilon_{M P R R} \text { when } \varepsilon_{M P R R}>0 \\
\Delta m_{p r e}=C_{1} \cdot k_{p} \cdot \varepsilon_{M P R R}+ \\
C_{2} \cdot k_{i} \int \varepsilon_{M P R R} \text { when } \varepsilon_{M P R R} \leq 0
\end{array}
$$

where $k_{p}$ and $k_{i}$ represent the proportional and the integral gain respectively, $C_{1}$ and $C_{2}$ are calibration constants (higher than 1) in order to get a faster response from the controller when the MPRR is reaching a value above the limit. Such control embeds an hysteresis for avoiding control instabilities and the desired MPRR limit was set to 12 bar/CAD in order to keep a safety margin from the limitation of $15 \mathrm{bar} / \mathrm{CAD}$.

\section{Results and discussion}

This section presents the results of the tests performed for validating the described combustion control concept. First, steady-state conditions were used to evaluate the ability of the controller to maintain desired performance while rejecting external disturbances. Then, a load transient test is presented to assess the controller capability under such conditions.

\subsection{Steady-state validation}

The operating points listed in Table 2 were selected for the steady-state evaluation of the controller. Operating point B represents a transition between RCCI FP and RCCI HP modes due to its load and resulting pressure derivative levels. Furthermore, a CACG transient with the operating conditions $\mathrm{D}$ is presented.

As previously highlighted, the closed-loop control is used to correct the control actions when the operating conditions deviate from the expected ones. Hence, various tests were performed varying parameters such as the intake pressure $\mathrm{P}_{\mathrm{int}}$, the EGR rate or the diesel injection pressure $\mathrm{P}_{\text {rail }}$ to validate the controller aptitude to reject eventual disturbances. The CACG target value was delivered by its look-up table from the open-loop control and is expressed in CAD after the top dead center (aTDC). The control variables $m_{t o t}, m_{\text {pre }}, G F_{\text {pre }}$ and $S O I_{\text {post }}$ were originally set by the open-loop values and then closed-loop corrected to reach desired performance. The controller potential is then evaluated testing the control of the IMEP and the CACG to a target value while keeping the MPRR under a safe threshold. In all the following graphs, the target value for IMEP and CACG and the limit value for MPRR are shown in a black line, the control and obtained variables are shown in a grey line and the $m_{t o t}$ in the $m_{\text {pre }}$ graph is shown in a dashed black line to distinguish their respective values when reaching a transition in the combustion mode. An additional graph shows the AHRR profile of three selected cycles shown in grey scale colour dots.

Figure 6 presents an EGR disturbance rejection test in a RCCI fully-premixed case. The EGR valve position was varied in order to modify the $\mathrm{CO}_{2}$ concentration at the intake. The controller shows the capacity to control the IMEP and the CACG within a mean absolute error of 0.09 bar and 0.28 CAD respectively. In this case the MPRR was not controlled due to the low levels obtained at this load and the total fuel 


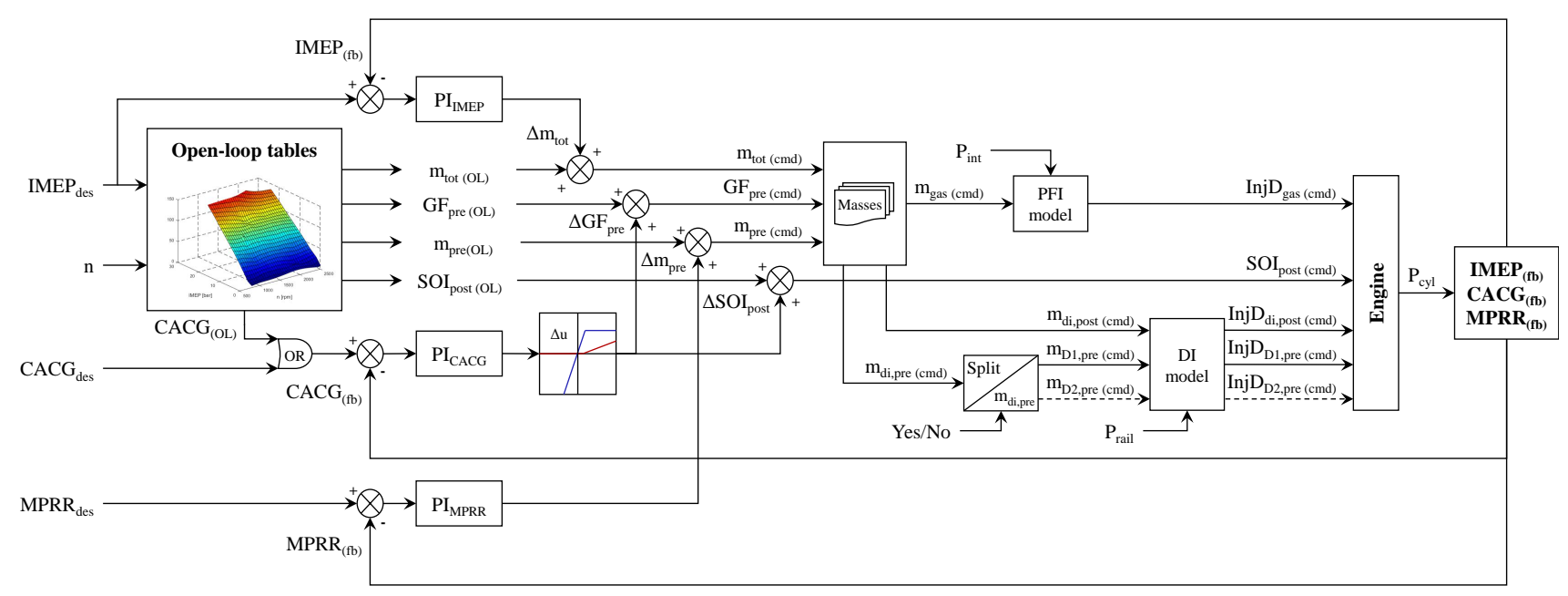

Figure 4. Closed-loop control structure - Abbreviations, $m$ : mass; pre: premixed; tot: total; gas: gasoline; di: diesel; $\operatorname{Inj} D$ : injection duration - Subscripts, des: desired; $c m d$ : command; $f b$ : feedback

Table 2. Operating conditions of steady-state experimental tests

\begin{tabular}{ccccccc}
\hline $\begin{array}{c}\text { Operating point } \\
-\end{array}$ & $\begin{array}{c}\text { Combustion mode } \\
-\end{array}$ & $\begin{array}{c}\text { Engine speed } \\
{[\mathrm{rpm}]}\end{array}$ & $\begin{array}{c}\text { IMEP } \\
{[\mathrm{bar}]}\end{array}$ & $\begin{array}{c}\mathrm{P}_{\text {int }} \\
{[\mathrm{b} \text { ar }]}\end{array}$ & $\begin{array}{c}\mathrm{P}_{\text {rail }} \\
{[\mathrm{bar}]}\end{array}$ & $\begin{array}{c}\text { EGR } \\
{[\%]}\end{array}$ \\
\hline $\mathrm{A}$ & RCCI (FP) & 1200 & 4 & 1.4 & 1200 & 0 to 58 \\
$\mathrm{~B}$ & RCCI (FP-HP) & 1200 & 8 & 1.8 to 2.7 & 1200 & 24 to 38 \\
$\mathrm{C}$ & RCCI (HP) & 1200 & 12 & 2.2 & 1000 to 1400 & 49 \\
$\mathrm{D}$ & Diffusive (DDF) & 1200 & 16 & 2.4 & 1200 & 45 \\
\hline
\end{tabular}

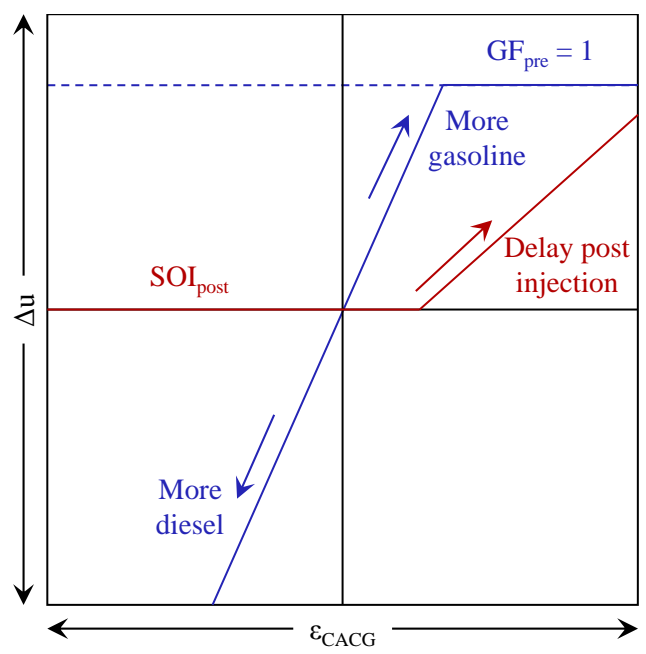

Figure 5. CACG control concept

mass $m_{t o t}$ is equal to $m_{\text {pre }}$ because the premixed charge is able to provide the desired load. The black dashed line corresponding to the total fuel mass is represented in the graph of $m_{\text {pre }}$ showing this observation. As expected, the increase in the EGR rate tends to delay the combustion and thus the gasoline fraction must be decreased to keep the combustion phasing constant ${ }^{44,45}$. It can be then observed that the controller decreases such variable and was able to maintain the IMEP by modulating the total injected fuel mass. Those effects can also be appreciated in the AHRR profiles where the three selected cycles show a very similar trend, resulting in an equivalent IMEP, CACG and MPRR.

In Figure 7 the intake manifold pressure is varied along the test in order to evaluate the control ability to keep the engine under desired performance at operating conditions B. Note that the EGR valve opening was set to a constant explaining the variation in the EGR rate at the intake as detailed in Table 2. As it can be seen, increasing the intake pressure involves an increase of the MPRR level resulting in a transition between RCCI fully-premixed and highlypremixed combustion modes. In this situation the pressure derivative level is detected as crossing the limit and thus activates the control of the MPRR (blue zone in the graphs). This transition can also be appreciated in the graph of the $m_{\text {pre }}$ evolution where the dashed line corresponds to the total injected fuel mass. It can be observed that the premixed charge is limited by the controller to maintain the MPRR level while $m_{t o t}$ is controlled to fulfill the load condition. When the intake pressure decreases enough to come back into RCCI FP mode, the MPRR control is deactivated. In RCCI FP mode, the cycle-to-cycle dispersion of the CACG has been stated to be an effect caused by the combustion in the engine itself due to the auto-ignition of the mixture, while the RCCI HP presents a reduced cycle-to-cycle variability with the use of the late diesel injection control. However, the dispersion obtained in the IMEP control, when the pressure derivative control is activated, has been found to be caused by some bias in the injectors models making the control a bit more unstable when trying to limit the MPRR level. Despite 

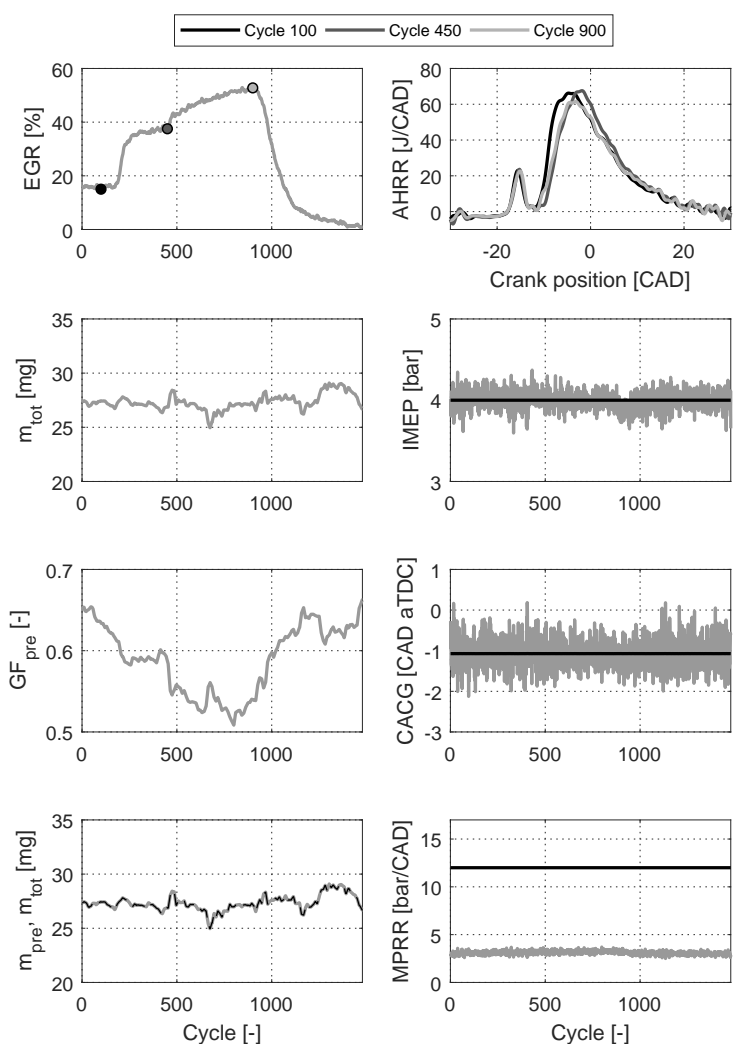

Figure 6. EGR variations at operating point $A$

such situation, the errors at the IMEP and the CACG control were found to be within a mean absolute error of 0.18 bar and $0.33 \mathrm{CAD}$ respectively, while the absolute difference between the MPRR and the desired limitation (in the blue zone) was about 0.75 bar/CAD. As it can be seen in the AHRR profiles, the increase in the intake pressure makes the combustion start earlier in both combustion modes. The slight differences between the profiles are also due to the difference in the total injected fuel mass and the cycle-tocycle dispersion of such combustion concept.

Figure 8 shows the results obtained in a test where the diesel rail pressure was varied in order to evaluate the controller ability to reject such variation while keeping IMEP, CACG and MPRR constant. This test was performed at the operating point $\mathrm{C}$ (RCCI HP) and varying the $\mathrm{P}_{\text {rail }}$ between 1000 and 1400 bar. In such combustion mode and load, the MPRR level could damage the engine and is hence controlled near the limit. The controller shows a global capacity to compensate such variations although some spikes in the load and the combustion phasing control can be observed when changing suddenly the rail pressure from 1200 to 1400 bar and opposite way. Such phenomenon could be explained by some inaccuracies in the injector model, which allows to convert the desired mass into injection duration (see Figure 4), in this area of rail pressure. The selected cycles present a similar AHRR profile showing that the controller is able to correct the injection settings to keep the engine under desired performance. Despite the stated spikes, the mean absolute error of the IMEP control is 0.13 bar, the one of the CACG control is about 0.5 CAD and the
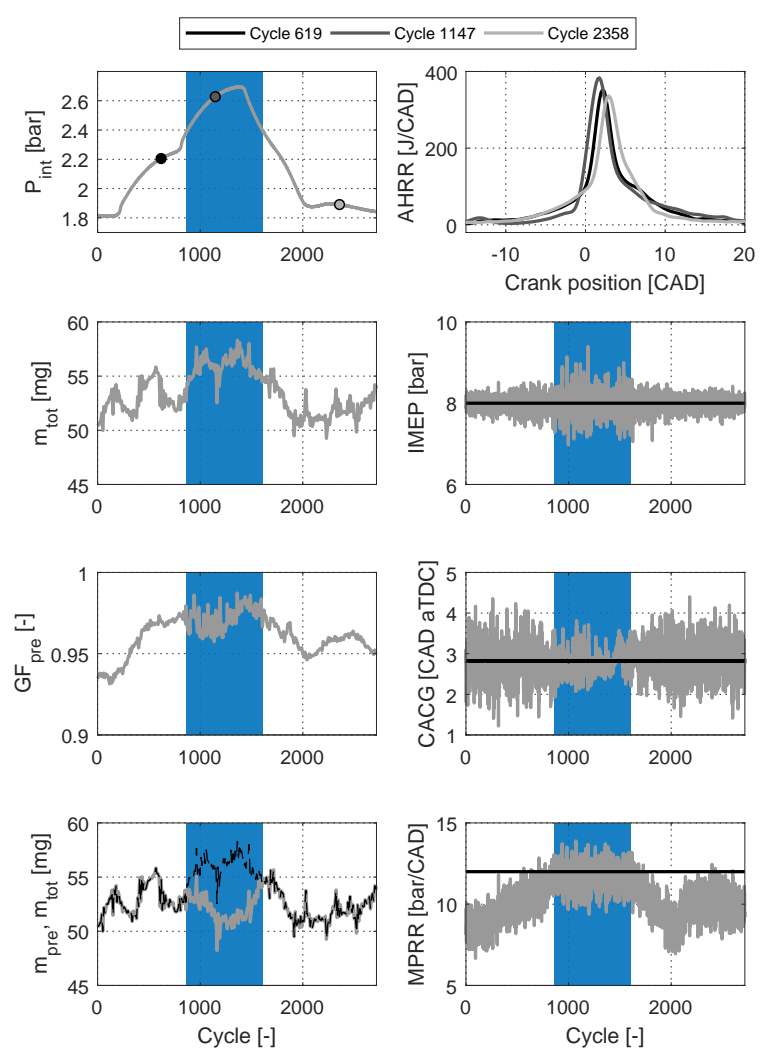

Figure 7. Intake pressure variations at operating point B: the MPRR control activation corresponds to the blue zone from cycle 860 to cycle 1600

absolute MPRR difference to limitation value is about 0.52 bar/CAD.

Finally, an experimental verification of the strategy presented in Figure 5 in a diffusive dual-fuel combustion is shown in Figure 9. In this figure the variations were performed in the desired CACG value. Steps in the expected combustion phasing were performed manually in order to validate the controller ability to correct the control variables and activate the use of the SOI of the post diesel injection to delay the combustion. As it can be seen, when delaying the combustion, the first control is applied by an increase in the gasoline fraction. Then, when this value approaches 1 , the combustion needs to be phased by the help of $S O I_{\text {post }}$. The effect of such strategy can also be appreciated on the graph representing the AHRR corresponding to the selected cycles (50, 240 and 380). Regarding the IMEP and the MPRR control it can be observed that both values are still controlled to the target and the limit value within a mean absolute error of 0.13 bar and 0.49 bar/CAD respectively. However, it was found that the controller lasts several cycles to reach the target value with a rise time about 30 cycles for the gasoline fraction control and about 80 cycles for the SOI control with a settling time of about 70 and 110 cycles respectively. This effect is explained by the smooth PI gains used in this study for the combustion phasing controller which were set to be less aggressive in order to ensure a proper MPRR and load control first. Nevertheless, a better PI gains tuning must be performed to improve the rise time of the controller. 

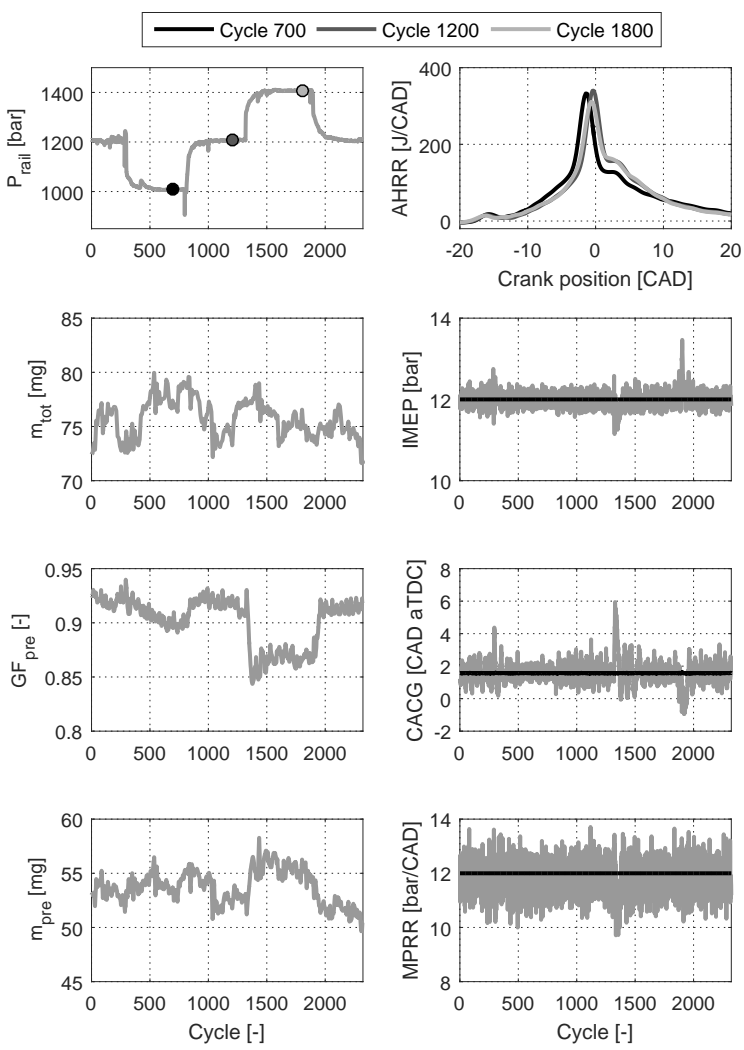

Figure 8. Diesel rail pressure variations at operating point $\mathrm{C}$
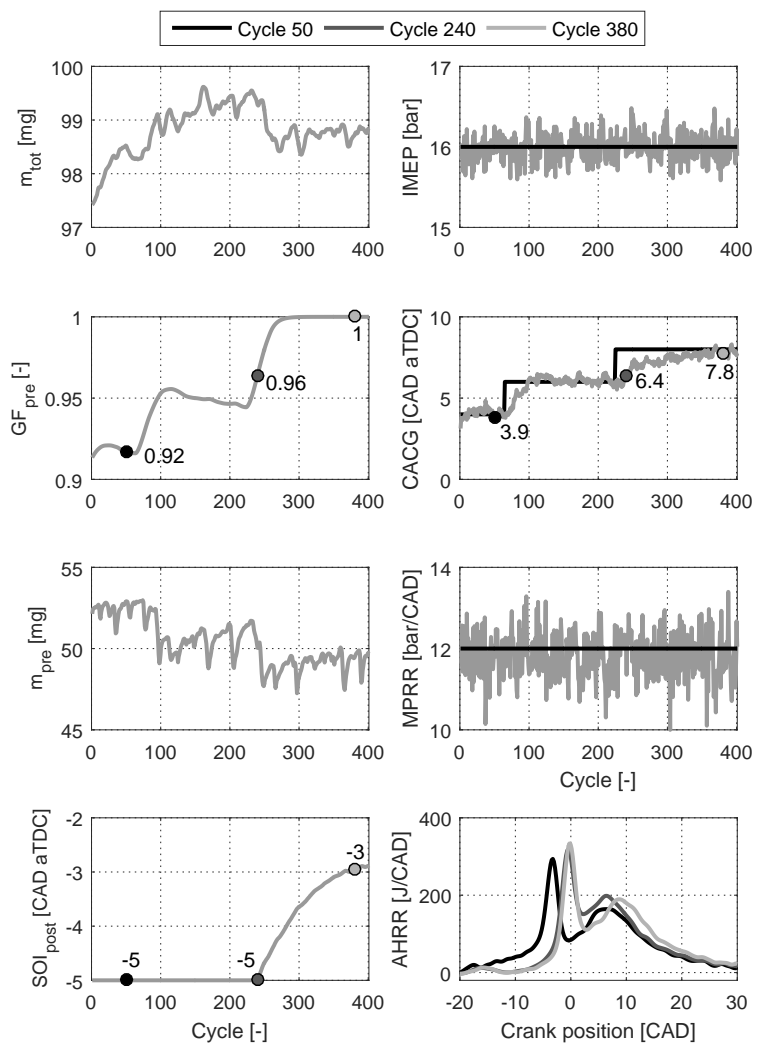

Figure 9. Activation of $S O I_{\text {post }}$ control to reach desired CACG at operating point $D$
With the aim to verify that the closed-loop controller was not resulting into an important source of cycle-to-cycle variation, the standard deviations $\sigma$ of four operating points in steady-state conditions were compared between dual-fuel operation in open-loop and closed-loop control. Figure 10 presents the results obtained from 100 recorded cycles for IMEP, CACG and MPRR standard deviations. Blue line/dots correspond to the open-loop control, red to the closed-loop one and black represents similar operating points in the same engine with conventional diesel combustion as a reference trend.

It can be observed that the closed-loop control tends to increase the standard deviation in the case of the IMEP and the CACG but still provides quite similar threshold to DFC-OL. Regarding the pressure derivative, at low load the MPRR is not controlled because of its low level regarding the limit. However, at 12 and 16 bar IMEP, when the control is activated, DFC-CL shows a similar standard deviation threshold to DFC-OL. In all the cases it can be seen that the dual-fuel combustion presents more cycle-to-cycle deviation than in CDC. This effect could be explained by the mixture and the auto-ignition process of such combustion strategy.

\subsection{Transient validation}

Figure 11 shows the experimental results of the proposed controller under load transient conditions. In this test a significant change in load is performed, from 5 to 24 bar IMEP, resulting also in a combustion switching-mode. In this case the switch in the combustion mode was detected by the controller due to the open-loop settings where an important fuel mass is injected through a late diesel injection as it can be seen in the top plot of Figure 11 (difference between $m_{\text {pre }}$ and $\left.m_{t o t}\right)$. The difference in combustion modes can also be appreciated in the bottom plot where the apparent heat release of three cycles are shown and where it is possible to observe the diffusive like combustion of the cycle 60 .

In the proposed strategy, the PI gains were programmed such that the load and the safety operation of the engine (MPRR) were of higher priority compared to the CACG control. Furthermore, in high transient operation, if operating conditions (intake pressure, oxygen concentration, etc.) are not satisfied fast enough, the injection settings could lead into significant overshoot in the MPRR. Thus, it was decided to limit the premixed mass $m_{\text {pre }}$ within a safe range for a few cycles at first.

Thanks to a proper calibration of the open-loop injection settings, and the PI gains tuning on load control, the controller was able to reach the desired IMEP within an absolute error of less than 1 bar under a rise time of 12 cycles and without overshoot. However the settling time was found to be about 25 cycles which must be improved in future work. Also, it is important to note that in this work the fuel transport dynamics from the port fuel injection at the intake were encompassed by the PI calibration due to the low effect of the PFI in this transient case where the main part of the load change was ensured by the late diesel injection, which does not present fuel transport dynamics (direct injection). However, in a case where the gasoline fraction would represent an important part of the load charge, such PFI transport dynamics effect should be included in the controller in order to improve its performance ${ }^{38}$. 

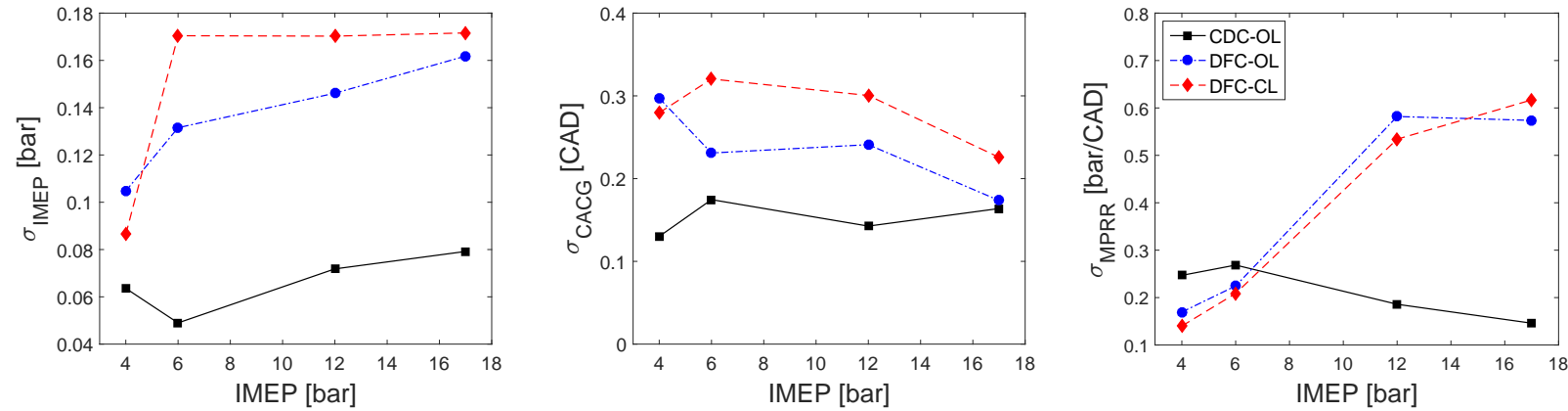

Figure 10. Standard deviation comparison at different loads between CDC-OL, DFC-OL and DFC-CL: standard deviations of IMEP (left), CACG (center) and MPRR (right)
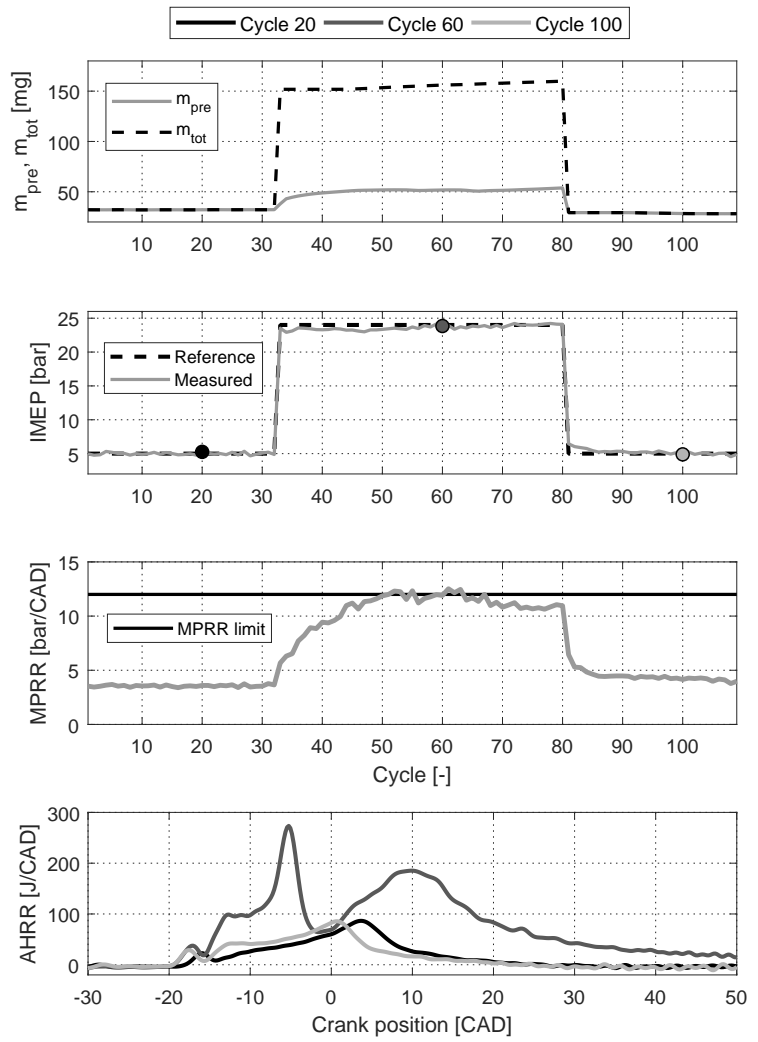

Figure 11. Controller performance under transient conditions at $1200 \mathrm{rpm}$

Furthermore, in transient conditions the residual gases from the previous cycle can affect the combustion of the next cycle $^{34}$ and thus this effect should be assessed. In this work, the change of the residual gases fraction from one cycle to the other was found to be small enough to be directly corrected by the PI actions. Finally, as previously highlighted with stationary conditions, the controller was able to maintain the MPRR at the desired limit value by modulating the premixed fuel mass. The mean absolute error of the IMEP control over the complete transient test was 0.3 bar with a peak at 1.5 bar error when decreasing the load around cycle 80 during 1 cycle.

\section{Summary and conclusion}

In this work a cycle-to-cycle closed-loop control has been investigated and applied to a dual-fuel combustion engine. In order to extend the dual-fuel operation up to high load, a diffusive dual-fuel combustion was used while RCCI combustion was performed at low load.

The presented controller was designed to control the load and the combustion phasing at a target value and to keep the pressure derivative level under a safe threshold. The proposed control concept was based on PI actions, the total injected fuel mass was used to control the load and the gasoline fraction for controlling the combustion phasing which, in this work, was considered as the combustion centroid. However, when reaching high loads, this latter parameter could not be used for delaying more the combustion and thus the SOI of the late diesel injection was used to reach the expected combustion phasing. While low load operation presented low MPRR levels, high loads combustion modes showed the need to limit such variable in order to avoid engine damage. The control strategy applied on MPRR was achieved by varying the premixed charge to maintain the pressure derivative at a safe limit. The developed controller proved the ability to activate such control in a transition between RCCI fully-premixed and RCCI highly-premixed but also in diffusive dual-fuel mode.

The controller validation was performed through various steady-state experimental tests showing the capacity to maintain the expected performance under an acceptable cycle-to-cycle dispersion while rejecting disturbances such as EGR, intake pressure and diesel injection pressure variations. Finally, a load transient showed that the developed control strategy was able to track the desired IMEP within acceptable error while switching from one combustion mode to the other without getting over the mechanical constraints.

\section{Funding}

The authors acknowledge the support of Spanish Ministerio de Economía, Industria y Competitividad through project TRA201678717-R. Alvin Barbier received a funding through the grant ACIF/2018/141 from the Generalitat Valenciana and the European Social Fund.

\section{Declaration of conflicting interests}

The authors declare that there is no conflict of interest. 


\section{References}

1. Kusaka J, Sueoka M, Takada K et al. A basic study on a ureaselective catalytic reduction system for a medium-duty diesel engine. International Journal of Engine Research 2005; 6(1): 11-19.

2. Hull A, Golubkov I, Kronberg B et al. Alternative fuel for a standard diesel engine. International Journal of Engine Research 2006; 7(1): 51-63.

3. Sung K, Kim J and Reitz RD. Experimental study of pollutant emission reduction for near-stoichiometric diesel combustion in a three-way catalyst. International Journal of Engine Research 2009; 10(5): 349-357.

4. Johnson TV. Review of diesel emissions and control. International Journal of Engine Research 2009; 10(5): 275285.

5. Yun $\mathrm{H}$ and Reitz RD. Combustion optimization in the lowtemperature diesel combustion regime. International Journal of Engine Research 2005; 6(5): 513-524.

6. Alriksson M and Denbratt I. Low Temperature Combustion in a Heavy Duty Diesel Engine Using High Levels of EGR. SAE Technical Paper 2006; 2006(724): 75-2006.

7. Stanglmaier RH and Roberts CE. Homogeneous Charge Compression Ignition (HCCI): Benefits, Compromises, and Future Engine Applications. In SAE Technical Paper. 724.

8. Aceves SM, Flowers DL, Martinez-Frias J et al. HCCI Combustion: Analysis and Experiments. SAE Technical Paper 2001; 2077(1): 9.

9. Kook S, Bae C and Kim J. Diesel-fuelled homogeneous charge compression ignition engine with optimized premixing strategies. International Journal of Engine Research 2007; 8(1): 127-137.

10. Ogawa $\mathrm{H}$, Azuma $\mathrm{K}$ and Miyamoto $\mathrm{N}$. Combustion control and operating range expansion in an homogeneous charge compression ignition engine with suppression of lowtemperature oxidation by methanol: Influence of compression ratio and octane number of main fuel. International Journal of Engine Research 2007; 8(1): 139-145.

11. Yao $M$, Zheng $Z$ and Liu H. Progress and recent trends in homogeneous charge compression ignition (HCCI) engines. Progress in Energy and Combustion Science 2009; 35(5): 398 437.

12. Reitz RD. Directions in internal combustion engine research. Combustion and Flame 2013; 160(1): 1-8.

13. Imtenan S, Varman M, Masjuki HH et al. Impact of low temperature combustion attaining strategies on diesel engine emissions for diesel and biodiesels: A review. Energy Conversion and Management 2014; 80: 329-356.

14. Paykani A, Kakaee AH, Rahnama P et al. Progress and recent trends in reactivity-controlled compression ignition engines. International Journal of Engine Research 2016; 17(5): 481524.

15. Hanson RM, Kokjohn SL, Splitter DA et al. An Experimental Investigation of Fuel Reactivity Controlled PCCI Combustion in a Heavy-Duty Engine. SAE International Journal of Engines 2010; 3(1): 2010-01-0864.

16. Kokjohn SL, Hanson RM, Splitter DA et al. Fuel reactivity controlled compression ignition (RCCI): a pathway to controlled high-efficiency clean combustion. International Journal of Engine Research 2011; 12(3): 209-226.
17. Molina S, Garcia A, Pastor JM et al. Operating range extension of RCCI combustion concept from low to full load in a heavyduty engine. Applied Energy 2015; 143: 211-227.

18. Wissink ML, Lim JH, Splitter DA et al. Investigation of Injection Strategies To Improve High Efficiency RCCI combustion with diesel and gasoline direct injection. Asme Icef2012-92107 2012; : 1-12.

19. Reitz RD and Duraisamy G. Review of high efficiency and clean reactivity controlled compression ignition (RCCI) combustion in internal combustion engines. Progress in Energy and Combustion Science 2015; 46: 12-71.

20. Benajes J, Molina S, García A et al. Effects of direct injection timing and blending ratio on RCCI combustion with different low reactivity fuels. Energy Conversion and Management 2015; 99: 193-209.

21. Splitter D, Wissink M, Kokjohn S et al. Effect of Compression Ratio and Piston Geometry on RCCI Load Limits and Efficiency. SAE Technical Paper 2012;

22. Benajes J, Pastor JV, García A et al. A RCCI operational limits assessment in a medium duty compression ignition engine using an adapted compression ratio. Energy Conversion and Management 2016; 126: 497-508.

23. Benajes J, Garcia A, Monsalve-Serrano J et al. Achieving clean and efficient engine operation up to full load by combining optimized RCCI and dual-fuel diesel-gasoline combustion strategies. Energy Conversion and Management 2017; 136: 142-151.

24. Shaver GM, Roelle MJ, Caton PA et al. A physics-based approach to the control of homogeneous charge compression ignition engines with variable valve actuation. International Journal of Engine Research 2005; 6(4): 361-375.

25. Caton PA, Song HH, Kaahaaina NB et al. Residualeffected homogeneous charge compression ignition with delayed intake-valve closing at elevated compression ratio. International Journal of Engine Research 2005; 6(4): 399-419.

26. Dempsey AB, Walker NR, Gingrich E et al. Comparison of low temperature combustion strategies for advanced compression ignition engines with a focus on controllability. Combustion Science and Technology 2014; 186(2): 210-241.

27. Ritter D, Andert J, Abel D et al. Model-based control of gasoline-controlled auto-ignition. International Journal of Engine Research 2018; 19(2): 189-201.

28. Haraldsson G, Tunestal P, Johansson B et al. HCCI Combustion Phasing with Closed-Loop Combustion Control Using Variable Compression Ratio in a Multi Cylinder Engine. SAE Technical Paper 2003;

29. Huang Y, Yang F, Ouyang $M$ et al. Optimal Feedback Control with in-Cylinder Pressure Sensor under Engine Start Conditions. SAE Technical Paper 2011;

30. Carlucci AP, Laforgia D, Motz S et al. Advanced closed loop combustion control of a LTC diesel engine based on in-cylinder pressure signals. Energy Conversion and Management 2014; 77: 193-207.

31. Olsson Jo, Tunestål P and Johansson B. Closed-Loop Control of an HCCI Engine. SAE Technical Paper 2001;

32. Ott $\mathrm{T}$, Zurbriggen $\mathrm{F}$, Onder $\mathrm{C}$ et al. Cylinder individual feedback control of combustion in a dual fuel engine, volume 7 . IFAC, 2013.

33. Hanson R and Reitz RD. Transient RCCI Operation in a LightDuty Multi-Cylinder Engine. SAE International Journal of Engines 2013; 6(3): 2013-24-0050. 
34. Khodadadi Sadabadi K and Shahbakhti M. Dynamic Modelling and Controller Design of Combustion Phasing for an RCCI Engine. In ASME 2016 Dynamic Systems and Control Conference. ASME, p. V002T20A004.

35. Kondipati NNT, Arora JK, Bidarvatan M et al. Modeling, design and implementation of a closed-loop combustion controller for an RCCI engine. In 2017 American Control Conference (ACC). IEEE, pp. 4747-4752.

36. Arora JK and Shahbakhti M. Real-Time Closed-Loop Control of a Light-Duty RCCI Engine During Transient Operations. SAE Technical Paper 2017; .

37. Indrajuana A, Bekdemir C, Luo X et al. Robust Multivariable Feedback Control of Natural Gas-Diesel RCCI Combustion. IFAC-PapersOnLine 2016; 49(11): 217-222.

38. Raut A, Bidarvatan M, Borhan $\mathrm{H}$ et al. Model Predictive Control of an RCCI Engine. In 2018 Annual American Control Conference (ACC). IEEE, pp. 1604-1609.

39. Indrajuana $A, B e k d e m i r ~ C$, Feru $E$ et al. Towards Model-Based Control of RCCI-CDF Mode-Switching in Dual Fuel Engines. In SAE Technical Paper. pp. 1-13.

40. Luján JM, Galindo J, Serrano JR et al. A methodology to identify the intake charge cylinder-to-cylinder distribution in turbocharged direct injection Diesel engines. Measurement Science and Technology 2008; 19(6): 65401.

41. Brunt MFJ and Pond CR. Evaluation of Techniques for Absolute Cylinder Pressure Correction. SAE Technical Papers 1997; (412): SAE 970036.

42. Asad $U$ and Zheng M. Fast heat release characterization of a diesel engine. International Journal of Thermal Sciences 2008; 47(12): 1688-1700.

43. Payri F, Broatch A, Salavert JM et al. Investigation of diesel combustion using multiple injection strategies for idling after cold start of passenger-car engines. Experimental Thermal and Fluid Science 2010; 34(7): 857-865.

44. Kokjohn SL, Hanson RM, Splitter DA et al. Experiments and Modeling of Dual-Fuel HCCI and PCCI Combustion Using InCylinder Fuel Blending. SAE International Journal of Engines 2009; 2(2): 2009-01-2647.

45. Desantes JM, Benajes J, García A et al. The role of the in-cylinder gas temperature and oxygen concentration over low load reactivity controlled compression ignition combustion efficiency. Energy 2014; 78: 854-868.

\section{A Combustion phasing evaluation}

The combustion phasing is usually considered as the crank angle where $50 \%$ of the total energy content of the fuel has been released, named the CA50. However, some control instabilities have been found using such parameter as shown in the top plot of Figure 12. Indeed, in some operating conditions, when using a post diesel injection at high loads (close to the TDC), the CA50 estimation could correspond to the exact transition between the premixed and the late combustion (see bottom plot). In the case presented in Figure 12 , the first part represents $50 \%$ of the total fuel mass injected and is composed by mainly well premixed gasoline $\left(G F_{p r e}\right.$ is about $85 \%$ ) and a small part of premixed diesel, while the second part is only composed by late diesel injected fuel. The diesel fuel injections are shown in blue in the bottom plot of Figure 12, the gasoline injection was injected at 340 CAD-bTDC and is not shown in this graph. It can
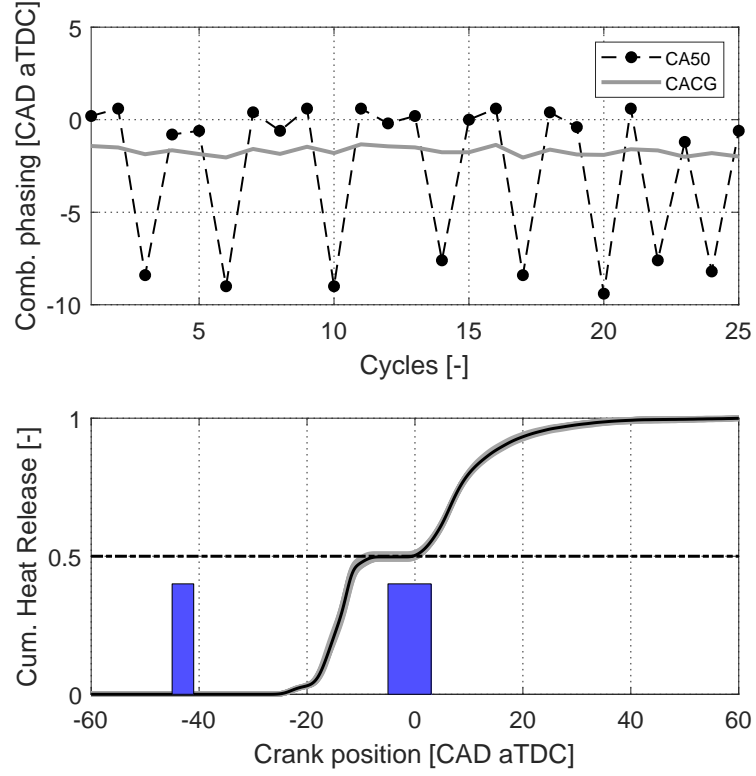

Figure 12. CA50 dispersion (1200 rpm-15 bar IMEP): CA50 (black dashed dotted line) and corresponding CACG (grey line) in top plot, and associated CHR profiles (grey: cycle-to-cycle, black: mean) with CA50 level (black dashed dotted line) in bottom plot. The blue squares represent the diesel fuel injections

be observed that in those specifics conditions, the premixed diesel was in enough quantity to increase the reactivity of the mixture and thus makes that charge to burn early in the cycle. Therefore, when the post diesel injection is performed, the previous premixed combustion is about to finish and thus, in this condition, this late injection ( $S O I_{\text {post }}$ at $5 \mathrm{CAD}$ bTDC) creates a second combustion phase. Hence, in order to adapt the combustion phasing control up to high load operation, a different parameter that the authors named the Crank Angle combustion Center of Gravity (CACG), also known as the combustion centroid, was used. This value consists in an energy balance from the AHRR as presented in equation (8):

$$
C A C G=\frac{\int_{S O C}^{E O C} A H R R(\theta) \cdot \theta \cdot d \theta}{\int_{S O C}^{E O C} A H R R(\theta) \cdot d \theta}
$$

where the SOC and the End Of Combustion (EOC) values are considered as the CA10 and CA95, respectively. As it can be seen in a grey line in the top plot of Figure 12, the CACG shows a better behaviour for a closed-loop control application than the CA50. 